\title{
Communicative interventions for collective action in the management of potato late blight: evidence from a framed field game experiment in Ethiopia
}

\author{
Elias Damtew ${ }^{1,2}$ (D) $\cdot$ Cees Leeuwis $^{1} \cdot$ Paul C Struik $^{3} \cdot$ Francesco Cecchi $^{4} \cdot$ Barbara van Mierlo $^{1} \cdot$ Rico $^{1}$ Lie $^{1}$. \\ Berga Lemaga $^{2} \cdot$ Katarzyna Cieslik ${ }^{1,5}$
}

Received: 12 May 2020 / Accepted: 30 October 2020 / Published online: 17 November 2020

(C) The Author(s) 2020

\begin{abstract}
Potato late blight remains a threat to food security and livelihood of millions of people in Ethiopia. Despite a rapid dispersal of the disease pathogen and farmers' interdependency in managing it, the literature on agricultural extension and communication tends to frame the disease and its management as a problem of the individual farmer. This study appreciates late blight as a collective action problem whose management requires a corresponding re-configuration in information sharing and communicative practices. We employ a framed field game experiment with a mixed quantitative and qualitative method to explore how and to what extent different types and combinations of communicative interventions affect collective action in the management of the disease among farmers in Ethiopia. Interestingly, our quantitative findings revealed that the provision of technical information about interdependency involved in the management of the disease and social monitoring information about the management practices of other farmers negatively affected collective action. However, collective action performance significantly improved when farmers were given the opportunity to interactively communicate about their management strategies. Further qualitative investigation sheds light on how farmers used and made sense of the different communicative interventions to inform and adjust their individual decisions, coordinate collective strategies, pressure free-riders, and develop a shared identity. It is concluded that interventions that mainly promote the provision of technical and social information can be counterproductive in managing collective action problems such as late blight unless it is complemented with interactive communication and deliberation processes.
\end{abstract}

Keywords Potato late blight $\cdot$ Collective action $\cdot$ Communicative intervention $\cdot$ Information $\cdot$ Interdependency $\cdot$ Smartphones

Elias Damtew

elohan.we@gmail.com

1 Knowledge, Technology and Innovation Group, Wageningen University, Wageningen, The Netherlands

2 CGIAR Research Program on Roots, Tubers and Bananas (RTB), International Potato Center (CIP), Addis Ababa, Ethiopia

3 Centre for Crop Systems Analysis, Wageningen University, Wageningen, The Netherlands

4 Development Economics Group, Wageningen University, Wageningen, The Netherlands

5 Department of Geography, University of Cambridge, Cambridge, UK

\section{Introduction}

Potato late blight, caused by Phytophthora infestans (Mont.) de Bary, is the major bottleneck in potato production, a crop that holds promise for food security and livelihood improvement to millions of people in Ethiopia (Demissie 2019; Tsedaley 2014). Since late blight came to the spotlight for being the cause of the Irish potato famine in the $1840 \mathrm{~s}$, it has been the most studied (and still among the most destructive) potato diseases in many parts of the world (Campos and Ortiz 2019; Kirk and Wharton 2014). The disease develops and spreads rapidly under high relative humidity, moderate temperature, and substantial rainfall, and has the potential to destroy the whole potato field within a few days (Burke 2017; Kirk and Wharton 2014).

Rooted in traditional agricultural extension and technology adoption model (Rogers 1995), communicative research and 
development interventions to deal with the problem of late blight tend to frame the disease as a problem of the individual farmer. This is reflected in interventions that advocate a linear form of advisory approaches geared towards the promotion of adoption of disease management technologies and practices at the level of individual farmers or households (Pernezny et al. 2016; Tsedaley 2014; Bekele et al. 2012; Mekonen et al. 2011; Miller et al. 2006; Franc 1998). There is a normative expectation that something considered desirable can spread across a larger number of users (Peng et al. 2018; Leeuwis 2010). Nevertheless, recent studies in a resource-poor smallholder farmer context stress that the rapid dispersal of the late blight pathogen across farm boundaries gives the management of the disease a collective action problem feature (Damtew et al. 2018; Tafesse et al. 2018). Meaning, lack of control of the disease by any individual farmer imposes costs or losses on other nearby farmers and likewise, control efforts by one farmer can confer a benefit to other nearby farmers (Graham et al. 2019). Because of this characteristic of the disease and its causing agent, the management of late blight is regarded as one among specific types of collective action problems in the domain of "public bads" (e.g., infectious and invasive species, microbial resistance to antimicrobial agents, global warming, air pollution) (Costello et al. 2017).

In a broader sense, a collective action problem is a situation in which all individuals would be better off cooperating but fail to do so because of conflicting interests between individual and collective goals (Olson 2009). The role of information and communication in overcoming collective action problems has been highlighted in seminal papers (Ostrom 1992; Ostrom and Walker 1991; Sell and Wilson 1991) and more recent literature, mainly in the field of behavioral economics (Cabrales et al. 2016; Opdam et al. 2016; Reuben and Riedl 2013; Smith 2010; Milinski et al. 2008; Cardenas et al. 2004). In fact, Sell and Wilson (1991) argued that information and communication are among the most important factors to influence cooperative behavior among interdependent individuals in a collective action problem situation. In this regard, many game-based experimental studies have been conducted in laboratory and field settings to study how the provision of social monitoring information (about practices of others) and/ or group communication influence collective action among interdependent individuals. However, literature in the field of behavioral economics has put emphasis on social monitoring information with limited attention to other types of information that could highlight interdependency originating from the ecological characteristics of the collective action problem at hand. For instance, Steingröver et al. (2010) emphasized that information about the multiple biophysical features (e.g., pest and disease dynamics in crops, landscape services, habitat for biodiversity and antagonists) is a potentially powerful way of illuminating interdependencies and the need for collective action among members of a community. Similarly, the provision of technical information about interdependency in relation to the collective risk and benefits of individual management practices can play an important role in influencing collective action in the management of the disease. As a separate research topic, a large body of experimental evidence exists on the role of group communication in overcoming collective action problems. What is largely missing in the latter domain of research is a systematic investigation of the underlying mechanisms that can give a robust explanation of how or why group communication influences collective action.

As further conceptualized and argued in detail in Section 2, this study designed a framed field game experiment that brought together three different types of communicative interventions to stimulate collective action in the management of potato late blight in Ethiopia. The first intervention was to provide technical information about interdependency in managing the disease (fungicide spraying). The second intervention added social monitoring information, that is, information about the practices of other farmers. The third intervention added a group communication element that gave space for farmers to interactively communicate about their collective problem and its management.

Given the increased availability of ICTs (Information and Communication Technologies) in rural settings and their presumed ability to facilitate network formation, dialog, and learning, there is also a growing research interest in experimenting with different communicative and informational functions in collective action problem situations using such technologies (Cieslik et al. 2018; Bennett and Segerberg 2012). Mobile phones and related technologies can particularly play meaningful roles in facilitating communication among spatially and temporally distributed individuals (Bennett and Segerberg 2012). Correspondingly, the group communication (third intervention) was supported by an internet-supported smartphone application (Voxer) that enabled farmers to communicate through voice and text messages. Farmers were given smartphones and had the opportunity to talk to each other about their individual or collective strategies to deal with their collective problem.

This study is primarily interested in understanding how and to what extent the different types of communicative interventions influence farmers' collective action in the management of potato late blight. In doing so, it also assesses the potential advantages and disadvantages of using smartphones as a platform for group communication.

The paper proceeds as follows. Section 2 further details the theoretical argumentation that led to our specific hypotheses and research inquiries. Section 3 covers the methodology in which the experimental design, the experimental procedure, the game framing, and the quantitative and qualitative data analysis approaches are presented. The results of the study 
are reported in Section 4. Sections 5 and 6 presents the discussion and conclusion part, respectively.

\section{Literature review and hypotheses}

\subsection{Communicative interventions in collective action problems}

Communicative intervention is the professional use of communication to help resolve problematic situations or to achieve societal ends (Leeuwis and Aarts 2011; Leeuwis 2004). In the context of crop disease management in general, and that of late- light prevention and control in particular, the dominant form of communicative intervention has been agricultural extension (Pande et al. 2009; Ciancio and Mukerji 2008). Such type of communicative intervention is informed by early adoption theories and social-psychological models that aim to influence clients' innovation decisions in a direction deemed desirable by a communication intervener (e.g., Rogers 1995; Petty and Cacioppo 1986). Such individualistic perspectives have been criticized by recent scholarship in the field for their simplistic notion of adoption decision and the lack of attention for social and institutional dimensions of innovation (Leeuwis 2004). This is indeed a limitation in view of the fact that late blight management is a collective action problem as farmers are interdependent in their efforts in managing the disease. More in general, it has been argued that rural innovation has collective dimensions and that other forms of communicative intervention or innovation intermediations are needed (e.g., facilitation of learning or space for negotiation, conflict management, and everyday communication) (Leeuwis 2004). Communication interventions can have broader roles than providing information-based advisory services or applying persuasive strategies that are aimed at influencing individual behavior (Klerkx et al. 2009; Klerkx and Leeuwis 2008). Such innovation scholars, however, mostly look at collective dimensions and new forms of communicative interventions in terms of resolving coordination in multi-stakeholder settings (e.g., among actors in value chains). They have not particularly looked at the specific communicative challenges in collective action situations or in the management of public bads that involve interdependent individuals. In this paper, we deal with a horizontal and mutual type of interdependencies among farmers rather than the type of interdependencies in multi-stakeholder settings that can be vertical and multi-level. It is deemed that interdependent farmers involved in a collective action problem situation do not only need information on the ecological characteristics of the problem that make them interdependent, but they also require various types of information on the behaviors of others on which they depend to meaningfully govern their shared problem (Leeuwis and Aarts 2020; Ostrom 2009). In line with this broader function of information, we develop our hypotheses to test the effect of several communicative interventions on collective action among farmers involved in infectious crop disease management.

In the context of collective action problems, a communicative intervention can be designed around the provision of information with the aim of explicating the ecological features of the disease management problem that makes individuals interdependent (Peng et al. 2018; Ostrom 1999). Costello et al. (2017) argued that knowing the spatial connectivity induced by the mobility of public bad resources influences private decisions, which collectively can have important consequences for control across a spatial domain. In our study context, farmers have very limited knowledge of the spreading feature of the late blight pathogen and the collective risk and benefit of individual management decisions (Damtew et al. 2020; Tafesse et al. 2018). In this regard, evidence from a systematic investigation of the role of such type of communicative intervention in collective action problems is sparse. The first hypothesis is that knowing or having technical information on the interdependency that originates from the collective risk and benefit of the individual management practice could positively contribute to farmers' collective action or cooperation in managing late blight.

Hypothesis 1: Providing technical information about interdependency resulting from the collective risks and benefits of individual management practices will improve collective action among farmers in managing late blight.

Communicative interventions can also be designed around the provision of social monitoring ${ }^{1}$ information on behavior or practices of others involved in the management of collective action problems (Khadjavi et al. 2017; Martin et al. 2014; Milinski et al. 2008). There exists a large body of experimental literature in the economics field that attempted to examine the role of social monitoring information in collective action. A key motivation for these studies has been a disregard to the types of uncertainty that people face in real-life because of lack of behavioral information (Choi and Lee 2014; Andreoni and Petrie 2004). It is contended that in reality, decision-makers operate in a limited information environment or do not always have information on what others are doing to use the information as a reference point for future decisions (Martin et al. 2014; Andreoni and Petrie 2004). In this respect, evidences from a range of experimental studies presented inconsistent findings whereby some showed a positive effect of social monitoring information on collective action (Khadjavi et al. 2017; Janssen et al. 2010; Smith 2010; Crawford 1998), whereas others found no effect (Hashim et al. 2011; Marks and Croson 1999; Weimann 1994; Sell and Wilson 1991). However, none of the reviewed literature has made an attempt

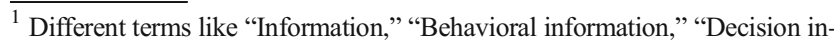
formation" are used in the economics literature.
} 
to examine the role of social monitoring information taking into account whether individuals have knowledge of the ecological characteristics of the problem that make them interdependent. Accordingly, we anticipate that having access to social monitoring information would positively contribute to collective action when farmers are aware of their interdependency from the collective risks and benefits of individual management practices. Moreover, the contribution of social monitoring information can depend on whether or not farmers know their interdependency from the collective risks and benefits of individual management practices.

Hypothesis 2: Providing social monitoring information on the management practices/decisions of others as well as technical information to make farmers aware of their interdependency will further enhance collective action among farmers.

and

Hypothesis 3: The role of social monitoring information on collective action is influenced by whether or not farmers have technical information about interdependency.

A separate strand of economics literature has its focus on understanding the role of group communication or "cheap talk" on collective action. By creating a sort of a discursive space, the opportunity to communicate is viewed as a mechanism that enables individuals to discuss, negotiate, or coordinate strategies to deal with their collective action problem (Balliet 2010; Dietz et al. 2003; Marks and Croson 1999; Ostrom 1992). A number of experimental studies reported a positive effect of communication on collective action (Cason et al. 2012; Bachi et al. 2010; Smith 2010; Bochet et al. 2006). However, taking into account the wider intermediary role of a communicative intervention, none of the reviewed literature made an attempt to integrate and investigate the effect of group communication together with the other types of communicative interventions (provision of social monitoring information and technical information about interdependency) on collective action. Accordingly, we hypothesize that:

Hypothesis 4: An opportunity to communicate on top of social monitoring information on practices of others and technical information about interdependency will result in the highest level of collective action in managing late blight.

\subsection{Beneath the relationship between communicative interventions and collective action}

Previous experimental studies are rarely supported with explanations of the mechanisms underpinning the relationship between communicative intervention and collective action. There is a limited evidence-based account of how or why a particular communicative intervention contributed to the observed variations in collective action. In this regard, we propound that a deeper examination of the role of communicative interventions in collective action problem situations is of considerable scientific and practical relevance. Some plausible explanations are suggested in literature as to how a group communication, as one specific type of communicative intervention, can influence collective action behavior. First, communication provides the opportunity to coordinate a collective strategy through clarifying confusion and facilitating discussions on incentives and trade-offs between individual and collective goals. Second, communication can also help people offer or extract promises of cooperation and detect and pressure free-riding behaviors. A third explanation is that communication permits subjects to create or reinforce a sense of group identity that could help motivate cooperative behavior (Peng et al. 2018; D'Exelle et al. 2012; Garicano and Wu 2012; Balliet 2010; Cardenas et al. 2004; Dietz et al. 2003). Informed by these perspectives on group communication and other emergent themes for the other types of communicative interventions, this study qualitatively explains how our communicative interventions influenced collective action behaviors in the management of late blight.

Similarly, in any type of communicative intervention, the medium of communication potentially has a number of enabling or constraining functional qualities (Leeuwis 2004). As our group communication was supported with an internet-enabled smartphone application, we are further interested in assessing the implication of using the platform as part of the wider role of the group communication environment. This means that our focus is not to investigate the contribution of the platform to collective action performance. Instead, our interest lies in assessing specific challenges, advantages, or disadvantages of using the platform as one type of communication channel when farmers communicate to coordinate their strategies or pressure free-riding behavior, or create/develop a shared identity in the management of their collective problem.

\section{Methodology}

The study is based on a mixed quantitative and qualitative analysis of a framed field game experiment conducted with real-life potato growers suffering from potato late blight disease. In line with the order of our research inquiry, the methodology section has two major sub-sections. The first subsection (3.1-3.3) covers the quantitative part on the experimental design and procedure, the game framing, the data source, and method of analysis. The second sub-section (3.4) describes the data collection and analysis for the qualitative part of the study. 


\subsection{Experimental design}

Our experiment simulated the management of potato late blight as a collective action problem whereby farmers have to make individual decisions/actions to spray or not to spray their own field but their level of success to control the disease depends not only on their individual action but also on the actions of other neighboring farmers. It was hypothesized that the proportion of farmers that are in a group meeting, the threshold (level of collective action) would be different for the types of communicative interventions.

Four experimental conditions were used to investigate how farmers respond to the different types of communicative interventions. Hence, the roles of the different types of communication interventions were tested under four intervention conditions against a non-intervention condition (Table 1).

1. In the non-intervention, farmer groups were not provided with any of the information types (technical information and social monitoring information) and were not given the opportunity to communicate with each other.

2. In the 1st intervention, the farmer groups were provided with technical information about interdependency or the collective risk and benefit of individual spraying practices (Hypothesis 1).

3. In the 2 nd intervention, the farmer groups were provided with technical information about interdependency and social monitoring information on the spraying decisions of others (Hypothesis 2).

4. In the 3rd intervention, the farmer groups were only given social monitoring information on the spraying decisions of others (Hypothesis 3 ).

5. In the 4th intervention, on top of technical information about interdependency and social monitoring information, the farmer groups had the opportunity to communicate with each other (Hypothesis 4).

A total of 225 farmers were involved from the Wolmera district in the central highlands of Ethiopia. Out of the 23 rural kebeles $^{2}$ in the district, nine kebeles with extensive potato production were purposely selected. From a list of all villages (got'es) within a kebele, five villages were then randomly drawn. Finally, five farmers were randomly selected from all inhabitants of each village making a total of 25 participant farmers from each kebele. The farmers from one village were distributed randomly over the five intervention and nonintervention groups. In this way, we reduced a potential bias we could have encountered if neighboring farmers in the noncommunicating groups would have a chance to physically identify each other, hence communicate. Thus, each

\footnotetext{
${ }^{2}$ The smallest official government administrative unit in Ethiopia
}

intervention and non-intervention condition was tested with 45 farmers (9 groups of five farmers) from the diverse kebeles.

\subsection{Implementation procedure}

The experiment was conducted in the nine kebeles one after the other, and each experiment or game session took three days per kebele following a standard procedure. First, the objective of the experiment was explained and farmers' willingness to participate was obtained. It was also made clear to them that if they happen to be in the communication intervention group, their conversation would be recorded on the smartphone for a research purpose and this was confirmed with a consent form. Farmers from the same village then drew a lottery to go into the different intervention and nonintervention groups and were given a unique identifier. All participants from all groups were then administered with a registration checklist containing general socio-economic and potato production practice-related questions. Two parallel information-sharing sessions that approximately took $45 \mathrm{~min}$ were held with farmers in all intervention and nonintervention groups. The session for intervention 1, intervention 2 , and intervention 4 was about the interdependency originating from the collective risk and benefit of individual management practices. The session with farmers in the nonintervention and intervention 3 was on potato nutrition, a topic with little connection to their fungicide spray decision making choices. All the farmers then came together for a chart-based explanation on the game framing as detailed in Section 3.3.

\subsection{Game framing}

Farmers were informed that they would be compensated for their time in the game, they were guaranteed to take home 600 Ethiopian Birr (about 22 USD then), and in the best-case scenario, they could take home 1200 ETB. It was explained that they were going to participate in a game where they all played themselves as potato farmers. It was emphasized that late blight is a disease that can spread from field to field, as it is air-borne, and any unsprayed field at the time of disease occurrence would be a source of infection to neighboring fields. In reality, all farmers spray fungicide to control late blight and the point of the game was for them to decide about fungicide spraying which is a real-life investment that they make to control the late blight disease. They could choose not to spray, to spray once, twice, thrice, or four times during the whole game. The game with four rounds was assumed to represent one potato growing season as farmers also make multiple spraying decisions in a particular growing season. They were informed that the game was played in a group of five people that were anonymous to each other and the group success in managing late blight depended not only on the decision of the individuals but also on the decisions of others in the group. 


\begin{tabular}{ll}
\hline Non-intervention & No technical information; no social monitoring information; no communication \\
\hline Intervention 1 & Technical information \\
Intervention 2 & Technical information and social monitoring information \\
Intervention 3 & Social monitoring information \\
Intervention 4 & Technical information; social monitoring information; communication \\
\hline
\end{tabular}

Before the first game round, everyone received an initial endowment of 600 ETB which symbolized the amount of money they spent to buy the required quantity of fungicide in a particular growing season. If their decision was to spray, they needed to put a 100 ETB note in an envelope and secretly put it in a ballot box. If they chose not to spray, they would submit an empty envelope.

If a group reached a total investment of 1500 ETB by the end of the fourth round, it meant that they managed to protect their field from late blight. If their investment was below 1500 ETB, the disease hit and caused damage. After the end of the fourth decision, there would be a harvest time that depended on their individual and group contribution or the number of fungicide application.

1. When a group managed to reach the threshold of 1500 ETB, every player received an extra 600 ETB as a "successful harvest" money. Every player also kept the money they had left from their initial endowment of 600 ETB. For instance, if a farmer sprayed only two times (200 ETB) and his group controlled the disease, he would receive $600 \mathrm{ETB}$ harvest money and also kept his remaining 400 ETB taking home a total of 1000 ETB. In this way, the amount of "take-home" money could differ between farmers based on their spraying decision creating a dilemma situation.

2. When a group did not reach the threshold of $1500 \mathrm{ETB}$, it meant that the spraying was not enough, the late blight hit the crop, and their harvest was affected. In such a case, if an individual in a group sprayed four times, it meant that $\mathrm{s} /$ he managed to control the late blight a bit and his/her harvest got him/her 400 ETB. Three times spraying got $\mathrm{him} / \mathrm{her} 300 \mathrm{ETB}$. Two times spraying got him/her 200 ETB. One time spraying got him/her 100 ETB. Zero spraying got him/her nothing or 0 ETB. Although the harvest money of individuals in a losing scenario depended on the number of individual sprayings, they also kept the money left in their pocket at the end and everyone finally took home 600 ETB. Apart from a way of compensating farmers for participating in the game, this was with the assumption that farmers, as rational decision-makers, normally aim for controlling the disease (get better harvest). However, they still have a dilemma situation or an incentive to free-ride and save more money in their pocket with the hope that other group members might contribute enough to control the disease.
After the explanation, all participants, with the exception of the communicating groups, went straight to making their first spraying decision. The communicating groups were separately given a small hands-on training on the use of the smartphones, the group communication app (Voxer) with a nudge that if they saw a need they would have a chance to communicate within their group members about the game. The communication groups then went to their first round of decisions.

The first decision was made on the first day, the second decision on the morning of the second day, the third decision in the late afternoon of the second day, and the last decision was made on the morning of the third day. Unlike the conventional multiple round game procedure (Milinski et al. 2008) where each round continued right after the former, we let players have at least eight hours between rounds so that farmers in the communicating group would have the opportunity to communicate if they saw the need. After each round of the game, only players in intervention 2,3 , and 4 were individually given social monitoring information or information on the decision of others in their group.

\subsection{Quantitative data and analysis}

Spraying decisions of 225 farmers from all intervention and non-intervention groups were used as the data source for the quantitative analysis. Within the different intervention and non-intervention groups, if a farmer was in a group that reached the threshold of 1500 ETB after 4 rounds of spraying decisions, $\mathrm{s} / \mathrm{he}$ was given a value of 1 and if $\mathrm{s} / \mathrm{he}$ was in a group that did not meet the threshold after 4 rounds of spraying decisions, s/he was given a value of 0 . Accordingly, we had 225 data points produced from a total of 900 spraying decisions. The effect of the four interventions (interventions 1, 2, 3, and 4) was compared relative to the nonintervention group. To improve the precision of our estimates, the measurement of the effect of the different interventions was controlled for individual attributes (age, sex, education, household size, potato farm size, perceived late blight seriousness, mainly seed producer, mainly ware producer, mobile phone ownership, and smartphone ownership) and kebele fixed effects. We used multiple linear regression to estimate our outcome variable which was the likelihood of reaching a goal (threshold) to control late blight under the different 
communicative intervention conditions. The model used to estimate reads:

$Y_{i}=C+\alpha T_{i}+\beta X_{i}+K+\varepsilon_{i}$

where $Y_{\mathrm{i}}$ is the value of the threshold variable for respondent $\mathrm{i}$, $T_{\mathrm{i}}$ is the intervention dummy, $C$ is the constant term or the value of $Y_{\mathrm{i}}$ when all the other variables are equal to zero. $X_{\mathrm{i}}$ is a vector of control for individual attributes, $K$ is the kebele fixed effect, and $\epsilon_{\mathrm{i}}$ is a random error term. $\alpha$ is the coefficient of interest identifying the effect of the interventions on reaching the threshold. The regressions were done on the STATA version 15.1 software package.

\subsection{Qualitative information and analysis}

In order to understand the underlying mechanisms as to how the different communication interventions were influencing farmers' decisions and the role of smartphones as a medium of communication, qualitative data were generated from two sources. Individual interviews were conducted with a total of 27 participant farmers, selecting 3 farmers from each kebele. The interviews were done right after the end of the game in each kebele so that farmers still had fresh memory on their overall experience. The checklist for the interviews was developed in such a way that it encouraged farmers to share their reflections on the different communicative interventions and the way they related the game with their real-life situation as potato growers. The second qualitative data source used to explain the mechanisms behind the quantitative findings was the recording of the phone conversations of the farmers that were given the opportunity to communicate. When farmers came to play between each round of the game, the records were constantly downloaded and the phones cleaned up for the next round of conversation. All the qualitative information from the interviews and the phone records were fully translated and transcribed from the local languages "Afan Oromo" and "Amharic."

The transcribed information from interviews and phone conversations were uploaded on ATLAS.ti software as separate files. Three code categories (Coordinating collective strategy, Discouraging free-riding behavior, and Creating a sense of group identity) were created in line with the reviewed conceptual literature on communicative intervention and collective action in Section 2.2. The transcribed information from the two different sources was then openly coded into the three code categories. An inductive analysis of the transcribed information also generated another three themes (Understanding interdependency, Learn about others' behavior and adjust own decision, and Implications of using the smartphones) that mainly investigated farmers' opinion and sense-making of the technical information on interdependency, social monitoring information, and (dis-)advantages of using the smartphones as a communication medium.

\section{Results}

In a brief descriptive part, Section 4.1 presents some general information about potato cultivation and late blight disease in the study sample area. Findings from the quantitative analysis related to our hypotheses are outlined in Section 4.2. Section 4.3 presents a qualitative explanation of how our communication intervention contributed to the observed differences in collective action. The last section (4.4) explores some of the contextual implications of using smartphones for communication.

\subsection{General information about the study population}

The livelihood of most farmers in the study area is primarily dependent on the cultivation of potato, cereals such as wheat, barley, and pulses such as faba beans and chickpeas. Some farmers also engage in off-farm activities, mainly as daily laborers in nearby private flower farms and a cement factory to generate additional income. As the study district is located in one of the biggest potatoproducing areas in the country, potato cultivation is by far the most important source of livelihood for farmers. Table 2 gives a general summary of the relative importance of potato cultivation to farmers' livelihood compared to other income sources in the study area. More than $99 \%$ of the respondent farmers labeled potato cultivation as very important or important.

Farmers' perception of the problem of late blight is another important factor in their efforts in managing the disease. The farmers rated the extent of the problem of late blight to their potato cultivation. The disease was categorized as either a serious or a very serious problem by $80 \%$ of the farmers and $99 \%$ of the respondent farmers labeled it as a problem (Table 3).

Table 2 Importance of potato cultivation for livelihood

\begin{tabular}{llcc}
\hline Rating & Frequency & Percent & Cumulative (\%) \\
\hline Very unimportant & 1 & 0.4 & 0.4 \\
Unimportant & 0 & 0.0 & 0.4 \\
Important & 20 & 8.9 & 9.3 \\
Very important & 204 & 90.7 & 100.0 \\
Total & 225 & 100.0 & \\
\hline
\end{tabular}


Table 3 Importance of late blight as a problem

\begin{tabular}{llcc}
\hline Rating & Frequency & Percent & Cumulative \\
\hline Not a problem & 2 & 0.9 & 0.9 \\
A mild problem & 43 & 19.1 & 20.0 \\
A serious problem & 63 & 28.0 & 48.0 \\
A very serious problem & 117 & 52.0 & 100.0 \\
Total & 225 & 100.0 & \\
\hline
\end{tabular}

\subsection{Variations among the different communicative interventions}

The regression outputs on the effect of the different communicative interventions on the level of collective action in the management of late blight are presented here.

\subsubsection{Hypothesis 1}

In the first hypothesis, we predicted that having technical information about interdependency on the collective risk and benefit of individual management practice (fungicide spraying) would have a positive effect on farmers' collective action performance. Contrary to our expectation, the interdependency information did not trigger farmers to collectively act (Table 4). In fact, while about $45 \%$ of the farmers were in the non-intervention groups that reached the threshold, with technical information about interdependency, only $33 \%$ of farmers were in groups reaching the threshold. The difference is not statistically significant.

\subsubsection{Hypothesis 2}

In the second hypothesis, we expected that additional social monitoring information on the decision of other group members (Table 4) would further enhance collective action among farmers. Interestingly, having such information on top of the technical information significantly worsened $(p=0.012)$ collective action performance. Again, conflicting with our hypothesis, the additional social monitoring information further impeded the performance of the groups; only $34 \%$ of the farmers were in groups that reached the threshold. This is the only intervention group where male farmers performed significantly better than their female counterparts. However, with the small number of female farmers ( 4 farmers) in the group, a note of caution is to refrain from using this information as evidence of a meaningful positive effect on male farmers than on their female counterparts.

\subsubsection{Hypothesis 3}

Our assumption was that the role of social monitoring information on collective action only is not sufficient to stimulate collective action and farmers need technical information about their interdependency in addition. However, our analysis (Table 4) showed that having only social monitoring information had a positive effect on farmers' collective action performance. In this intervention condition, $57 \%$ of the farmers were in groups that reached the threshold, which is $29 \%$ higher relative to the non-intervention condition. This provides evidence that the influence of social monitoring information on collective action indeed depends on whether or not farmers
Table 4 Communicative interventions and spraying threshold levels as a measure of collective action

\begin{tabular}{|c|c|c|c|c|}
\hline & $\begin{array}{l}\% \text { of farmers in } \\
\text { groups reaching } \\
\text { threshold }\end{array}$ & $\begin{array}{l}\text { Standard } \\
\text { error }\end{array}$ & $\begin{array}{l}P \\
\text { value }\end{array}$ & $\begin{array}{l}R \text { - } \\
\text { squared }\end{array}$ \\
\hline Non-intervention mean & 44 & & & \\
\hline Technical information about interdependency & 33 & $(0.0692)$ & 0.125 & 0.679 \\
\hline $\begin{array}{l}\text { Technical information about interdependency }+ \\
\text { social monitoring information }\end{array}$ & 34 & $(0.037)^{*}$ & 0.012 & 0.910 \\
\hline Social monitoring information & 57 & $(0.040) *$ & 0.002 & 0.912 \\
\hline $\begin{array}{l}\text { Technical information about interdependency }+ \\
\text { social monitoring information }+ \text { group } \\
\text { communication }\end{array}$ & 56 & $(0.039) *$ & 0.003 & 0.903 \\
\hline Kebele fixed effects & \multicolumn{4}{|l|}{ Yes } \\
\hline Additional controls & \multicolumn{4}{|l|}{ Yes } \\
\hline Observations & 225 & & & \\
\hline
\end{tabular}

$* p<0.05$. Additional controls include age, male dummy, education level, household size, potato farm size, perceived late blight seriousness; mainly seed producer; mainly ware producer; mobile phone ownership; smartphone ownership. See Tables A1-A4 in the Supplementary material for full details of the control variables and their coefficients 
have technical information about their interdependency. This finding also signals the uncertainty of using only social monitoring information to explain the role of information in altering collective action performance.

\subsubsection{Hypothesis 4}

Finally, we predicted that allowing people to communicate on top of the technical information about interdependency and social monitoring information would produce the highest level of collective action. As can be inferred from Table 4, having the opportunity to communicate has noticeably improved collective action among the farmers in managing the disease. In this intervention condition, $56 \%$ of the farmers were in groups that reached the threshold. This is a significant $(p=0.003)$ increase of $27 \%$ relative to the performance of farmers in the nonintervention condition. The increase in performance was even more dramatic when one notices the neutralization of the negative effect of technical information and social monitoring information when the opportunity to communicate is given. In this regard, there was a $65 \%$ increase in collective action performance relative to the farmers in the intervention group that has both technical information and social monitoring information.

\subsection{How did the communicative intervention influence collective action?}

This result section presents detailed qualitative explanations underlying the observed effect of the communicative interventions on collective action. The first two themes (Sections 4.3.1 and 4.3.2) mainly relate to the communicative interventions on the provision of technical information and social monitoring information. The rest of the themes (Sections 4.3.3, 4.3.4, and 4.3.5) cover explanations about the role of group communication in influencing collective action performance.

\subsubsection{Understanding interdependency}

In contrast with the assumptions, farmers' awareness of their interdependency through technical information has actually encouraged them to pursue an individualistic goal or to freeride. Farmers' statements on why they would spray their field or advise neighbors to do the same when they saw late blight symptoms in their own or their neighbors' fields attested this tendency. On his new perspective on interdependency and the "benefit" that could come with it, a farmer said, "Today, we saw an interesting thing. We understood the transmission of potato late blight from someone's field to other farmers' fields. For example, if there are 10 hectares of potato field in an area and if 8 hectares got sprayed, the sprayed fields may help in reducing late blight on the fields that never got sprayed." Another farmer described the dilemma situation they were in, "There are some individuals in dilemma thinking about the advantage they may get from farmers spraying their potato field near their own field." Similarly, a farmer shared his opinion on why some farmers in his group did not contribute to the collective management of the disease, "The reason why some farmers didn't contribute to spraying is that they hoped that if their neighbors would spray, they would benefit from them.".

Contrary to this dominant tendency, the understanding of interdependency stimulated some farmers to be more cooperative or show altruistic behavior. A farmer stated his willingness to even compensate for other farmers, "I spray for fear of the spread of late blight to my field. Even if the person lacks money for buying a chemical, I have to help him in buying the chemical." The realization of this type of interdependency influenced another farmer to say, "So far, I have been doing nothing even if I see late blight on others' fields. But, after this training, I understood the importance of discussing with the other farmers and mobilize them for spraying in order to manage the disease. I also realize even to sue a person if $\mathrm{s} / \mathrm{he}$ is not willing to spray."

\subsubsection{Learn about others' behavior and adjust own decision}

The provision of social monitoring information on the decision of other group members after each round of the game appeared to stimulate farmers to adjust their own decision. Knowing about the choices of other farmers without being able to communicate with their group members, the farmers appeared to rely on their individual judgments only and make choices either to compensate for free-riders or to free-ride themselves. As can be seen in the following interview quotes, some farmers covered for free-riders within their groups. "When I heard others didn't contribute to managing the disease, I decided to provide extra contribution." was a statement from a farmer. Another frustrated farmer shared his experience, "I sprayed all the time because others were not, but it is sad we still failed!" Even though no farmer during the interview dared to say that $\mathrm{s} / \mathrm{he}$ free-ridded after learning the behaviors of others, our quantitative result has provided evidence that the effect of having additional information on the contribution of others negatively affected collective action performance. This meant that the dominant strategy was to decide to free-ride when farmers learned their group members were not contributing enough.

\subsubsection{Coordinating collective strategy}

Under the condition of group communication, the farmers discussed their performance after each round of the game and coordinated their collective spraying strategy. They explained their efforts to organize themselves in terms of a collective goal, "Well, I hear the voicemail and get all the suggestions from the other people and discuss how much is left to reach the target......; "We talked about the amount collected in each round and we made suggestions on the amount that needs 
to be contributed between rounds..."; "Three of us discussed how to get to the target but we failed as a group because two farmers were not communicating with us." Correspondingly, farmers being the subject of the other communicative interventions described how they could have benefited if they had a chance to interact before making decisions. A farmer uttered, "It would have helped us advise each other about what to do prior to giving decisions to spray or not to spray." Another farmer added, "we would have discussed that we have contributed this amount of money on the first round and advised each other on the amount of money to contribute on the second and third rounds."

Voice records on the smartphones of the communicating groups provided a strong account of the considerable effort devoted by farmers to calculate and check their collective performance. A farmer emphasized, "You heard our score and we missed 100 ETB today. Please let's try to compensate for the gap by contributing at least 200 birr." Another farmer voiced, "Today is the last day of the game. We, my group, have contributed around 1000 birr. So, contribute the rest and don't try to save the money." When a farmer realized that they had already met the target before the last round, he prompted, "We have contributed 1500 birr. So, don't contribute hereafter, because contributing more than 1500 is meaningless."

There was one striking finding that is of relevance in understanding the overall influence of the communicative interventions and particularly on farmers' efforts to coordinate a collective strategy. Despite their understanding of the disease controlling strategy in the game, some farmers tended to apply spraying practices they have in their real-life. Conversation records revealed how these farmers insisted to stick to their actual fungicide spraying routine even when they knew it did not correspond with the optimal strategy in the hypothetical scenario. A farmer asserted, "As you know, we have an experience of spraying up to four times in our area. According to the trainers, contributing 1500 birr (each spraying three times on average) is enough. But I don't think this is acceptable. Spraying four times is important to get better production. So, each of our group members has to contribute 100 Birr in all the four rounds." Another farmer voiced his dilemma as, "The plan for managing potato late blight is contributing 1500 birr or more. But from our experience, we spray a maximum of two times. If we contribute based on this experience, we will fail, what should we do?" In an attempt to guide his group members, a farmer said, "we know how many times we need to spray to control potato late blight. In this case, spraying one to two times is enough in managing the disease."

\subsubsection{Discouraging free-riding behavior}

For the reason explained in Section 3 of this paper, group members were anonymous to each other, consequently, farmers were not in a position to exactly discern between contributors and non-contributors. However, this did not stop farmers from putting pressure on free-riders when they knew that the group was not performing to their expectations. The phone records clearly captured that the pressure farmers were trying to exert on cheaters and mobilize other group members to do the same. A farmer denounced the act of an unknown cheater and called for intervention from the others saying, "We should struggle against the person who did not contribute to spraying." With what seemed to be categorizing the use of the money for another purpose as a deceitful act, a farmer commented, "I think there are some individuals who use the money for another purpose." A farmer who suspected that farmers, who sometimes sent their contributions through other farmers, could be the cheaters, said: "Those who are sending an empty envelope to another person keeping the money in your pocket have to stop such cheating."

It is also important to mention that interviewed farmers believed that the social pressure and, consequently, their collective performance could have been different if they had known for sure the free-riding individuals within their groups. "When I suspected someone is cheating, I only tried to strongly advise everyone" was a comment from a farmer who could not do more than using a triggering strategy. Another farmer expressed his regrets for not knowing the responsible person for their group failure, "For example, my group was made of five that later failed to control the disease because we were 100 Birr less than the threshold. We never got to know who was responsible!"

\subsubsection{Creating a sense of group identity}

Given the few days (3) the communicating group interacted, it is interesting to see that some forms of group identity emerged. The group communication seemed to initiate a potentially new identity as "joint late-blight managers," while initially, the farmers saw the disease as an individual problem and the need for collective management more or less was a new concept to them. A farmer stated, "When we communicate, it motivated us to work cooperatively for our shared goal which is to manage the disease that I now know I cannot do alone." This new form of identity is also reflected in the following statements when farmers cherished their new "expert" status and claimed responsibility for educating other members of the community that they believed had a different understanding of the disease and its management. On one of the phone records, a farmer elaborated to his group members "This chance is given us by God. So, what if our group members discuss the potato late blight? Think about it, it is something that may help us and further, we can teach our spouses at home." A farmer from another group commented, "We have to teach our society what we learned about the disease here."

When it came down to the group level, farmers were observed to share ideas on how to behave and act as one district 
collective. This quick identification of oneself as a member of a particular group is lucid in the voice record, "Hello my group how are you doing? What are you thinking? What is the status of our group?" A farmer reminded his group members, "Put the money in the envelope secretly without any advice from others". On the other hand, farmers were open to give or take advice from their own group members as an interviewed farmer illustrated, "Yes, people in my group were consulting about my decision to spray or not to spray by phone. And I told them my decision. They are my group members and since it is for mutual benefit, telling them my own decisions to spray or not to spray has no problem." Although farmers understood that their group performance was independent of other groups, they still displayed a competitive attitude or wanted to perform better than the others. In the interview, a farmer said, "We also wanted to be better than other groups, be competitive." A recorded farmer uttered, "I have heard that one of the other groups has contributed 400. My group members; please think carefully."

\subsection{Implications of using the smartphones}

Although the majority of participant farmers had never used smartphones and internet before our experiment, with the brief training, most of them were able to operate the smartphone and the application without much difficulty. As a particular type of communication platform, interviewed farmers mentioned some associated advantages and disadvantages that impacted the nature and quality of their communication in their efforts to collectively manage the disease and beyond. The challenges were mainly technical and skill-related on using the touch screen and the Voxer application, and the problem of stable internet connectivity in some of the study sites. Operating the smartphones was particularly difficult for older farmer participants of the experiment. An interviewed farmer commented, "The phone was difficult to use since we are not very familiar with such type of phone." "There was not much problem, but while I was touching, I lost the Voxer on the second day and could not receive and send a message" was a statement from another farmer. Some of these problems had consequences to their group performance according to a farmer who stated, "Three of us discussed how to get to the target but two of our group members were not able to communicate with us and because of those two, our group failed to manage the disease."

Opinions on the advantages, however, focus on the networking or connective features of the platform. Farmers mentioned interesting insights on the advantages of using the smartphones by putting them into perspective with their usual face-to-face communication. Emphasizing the connective power of the platform, a farmer stated, "It would have been difficult to meet up and share the different ideas, but because of the phone it was not tedious for us." Another farmer added,
"It helped me to discuss with my group members when I was at my work without getting the guys physically. That means we didn't need to contact our group members in person to discuss and share ideas about what to do."

The connective function of the platform is clearly seen in the phone conversations as farmers used the opportunity to discuss and share experiences on production practices of potato and other crops and on the importance of getting organized to deal with their market problems. Knowing that his group members are from different villages, a farmer asked, "If you have any experiences about potato from your area or from other people, let's share with each other." Another farmer responded, "Before planting a potato, we have to have our plan including the way and number of tillage and the season of planting. Then after, we have to apply fertilizer during planting and upper dressing. Spraying four times is mandatory.". On the problem of unfair market and the need to get organized to deal with powerful brokers dictating the market, a farmer commented, "There is a serious problem in potato marketing. There is no direct selling of potato to the traders so far. We have been selling potato production through brokers which is prohibiting us from getting the right price for the production. It is brokers who are getting more benefits at the expense of farmers." Another farmer voiced, "Let us unite and limit the interference of brokers in the market environment."

If we look into the functional peculiarities of the use of the smartphones as a group communication platform, one interesting encounter relates to the ability of such platforms to influence people to create a virtual identity or exhibit a sort of different character from the way they might behave under other means of communications such as face-to-face. While discussing the perceived advantage of the platform, a farmer said, "The phone has a great advantage, it helped me talk about anything that is on my mind without any shame. Some farmers were even singing to us."

\section{Discussion}

\subsection{The role of the communicative interventions}

Drawing upon a broader perspective on communicative practices, our study experimented with the role of different types of communicative interventions in the management of potato late blight as a collective action problem. To this end, we examined to what extent and how (1) technical information about interdependency, (2) social monitoring information with and without technical information about interdependency, and (3) interactive communication among farmers influenced their collective action in managing the disease. As highlighted earlier, previous studies on the role of communicative interventions are largely concentrated in behavioral economics and mainly attempted to measure the effect of 
social monitoring information and group communication as distinct areas of research interest (Khadjavi et al. 2017; Opdam et al. 2016; Hashim et al. 2017; Dietz et al. 2003; Crawford 1998). Our review also failed to find a study that set out to investigate the role of technical information about interdependency involved in management practices either in combination with other types of communicative interventions or as one typical case. In this regard, it was our assumption that in a context where farmers have very limited information on the collective risk and benefit of individual management practice, the provision of such information would trigger farmers to better cooperate in overcoming their collective problem. Our quantitative results demonstrated that the provision of technical information about interdependency did not improve farmers' collective action performance. The proportion of farmers that were in groups reaching the threshold (manage the disease) was about $25 \%$ lower relative to the non-intervention condition even though this negative effect was not statistically significant. Looking into the qualitative information on the way farmers made sense of the technical information as an opportunity to benefit from the spraying of other farmers, having such information could encourage farmers to work against the collective goal of managing the disease.

It was also argued that additional social monitoring information on spraying practices of others would further enhance collective action in managing the disease. Our results again revealed that having such additional information even worsen farmers' collective performance whereby the proportion of farmers that were in groups reaching the threshold was significantly lower $(p=0.012)$ than the non-intervention condition. Interestingly, farmers who were in groups only given social monitoring information performed 29\% relatively higher and significantly better than the non-intervention condition. Our hypothesis on the role of social monitoring information (Hypothesis 3) was in view of existing inconsistency in literature on the effect of such type of information, and hence, its effect could be influenced by whether or not farmers understand the ecological characteristics of the disease that makes its management a collective action problem. The result supports our hypothesis that the effect of social monitoring information could be affected by farmers' understanding of the collective nature of the disease problem and its management. It may be the case that if farmers are only provided with social monitoring information, they could use the information to pursue strategies that they think would maximize their income without relating their decisions to their real-life situation or the characteristics of the collective action problem at hand. As is further illustrated in our qualitative analysis, what can be inferred from the effect of both technical and social monitoring information, in a situation where awareness of interdependency (technical information) promotes free-riding behavior, knowing the less satisfactory collective performance (social monitoring information) could further encourage farmers to free-ride. When farmers that were in groups with both technical information and social monitoring information were given a chance to interactively communicate, they performed significantly better $(27 \%)$ than the farmer groups in the nonintervention condition and about $65 \%$ higher than farmers that were in the groups with both technical information and social monitoring information.

Against this background, our finding on the role of technical information about interdependency by no means leads to a conclusion that the provision of this type of information is detrimental to collective action in the management of the disease. Neither does the positive effect of social monitoring information lead to the suggestion that social monitoring of management decisions alone would be a solution to overcome collective action problems. Rather, as demonstrated in the communicating group and the qualitative findings, it underscores the importance of a combination of communicative interventions that goes beyond just providing information and creates room for farmers to interact, learn, and coordinate their actions towards a collective goal. As highlighted by Leeuwis and Aarts (2011), beyond the provision of relevant information, meaningful change depends on creating a space for human interaction and negotiation, and its formation is inherently dependent on an interactive form of communication.

\subsection{Mechanisms in interactive communication}

Previous studies on collective action problems have hypothesized or used qualitative case studies to explain the mechanisms under which interactive communication could influence collective action (Garicano and Wu 2012; Cardenas et al. 2004; Dietz et al. 2003; Ostrom and Walker 1991). Apart from employing such conceptual perspectives to substantiate the role of group communication, our study additionally attempted to integrate and inductively investigate how the provision of both technical and social monitoring information influenced collective action performance as reported in the quantitative findings. Through the analysis of interviews and phone conversations, the study provided explanations on the way farmers made sense of the information types to inform their individual decisions. Interesting accounts were captured that explained some of the underlying motives to pursue individual goals rather than a collective one or vice versa. A new appreciation of interdependency that stems from the collective nature of managing the disease, and the chance to inform their decisions based on the decision of others had a meaningful impact in shaping their cooperative behaviors. This brings a fresh perspective to existing literature that so far attempted to explain the role of information only from the perspective of social monitoring information or how knowledge on the propensity of others to cooperate influences collective action 
(Fischbacher and Gachter 2010; Croson and Shang 2008; Croson 2007). Farmers in the communicating groups used the opportunity to coordinate a collective strategy, to put pressure on free-riders, and to create a sense of group identity that explains the positive effect of the group communication on collective action performance. Because of the experimental design choice of our study, farmers in a group were anonymous and from the different statements of farmers, the anonymity seemed to negatively influence the role of the group communication especially in their attempt to discourage freeriding behavior. Even so, they tried to use the opportunity to arouse what Ostrom and Walker (1991) called "internal guilt" on individuals who were believed to have shown nonconforming behaviors. However, our study would not fall short of recognizing the premise that the type of social pressure in collective action problem situation is not only about individuals' perception of the wishes and norms of others but also involves dynamics of power and enforcement whereby the detection of individual behaviors becomes important (Leeuwis and Aarts 2020; Cubitt et al. 2011; Ostrom 1990). In general, having a good understanding of the underlying mechanisms would help in the development of an empirically validated theory that explains why communicative interventions would be (in)efficient in the management of collective action problems in a given situation. From a practical viewpoint, this also provides an opportunity to improve or adapt communicative intervention approaches around the management of collective action problems. For instance, the fact that some farmers tried to negatively influence other farmers by bringing their real-life spraying practice is one such contextual case that a communicative intervention could take into account to optimize its contextual relevance.

\subsection{Trade-offs associated with smartphone use}

Finally, our study also assessed the potential trade-offs of using smartphones as a medium of option for group communication. Our aim to look into the smartphone as a communication tool in a wider communicative intervention was rationalized by the fact that the mechanisms underlying the role of the group communication (e.g., coordinating collective strategy, pressuring free-riding behavior, or creating a sense of group identity) are considered to be consequences of the opportunity to communicate in general. However, it was in the interest of this study to unravel the potential trade-offs that could come along with the use of a particular type of communication platform. From this end, most of the disadvantages of using the smartphones were related to skills on the proper use of the smartphone and the problem of reliable internet connectivity. As much as physical infrastructural and knowledge gaps in the use of ICTs are common constraints mentioned in many studies, it is also becoming less and less persistent due to the growing investment and rapid ICT expansion in rural Africa (Asongu and Boateng 2018; Maumbe and Okello 2013; Adam 2012). Despite some challenges expressed by few interviewed farmers, our quantitative results also corroborated that previous exposure or being an owner of a mobile phone or a smartphone was not a significant factor to influence collective action in both the intervention and nonintervention groups. In contrast, an important advantage of using the smartphone relates to its connective power that allowed farmers to discuss their strategies when they were physically distant to each other. The ability of ICT to overcome geographic barriers has already been an established notion with the potential of facilitating new forms of collective action or what Bennett and Segerberg (2012) call "connective action." Likewise, the use of smartphones has also signaled a prospect for catalyzing wider connectivity beyond the community as farmers discussed other issues such as market problems and the idea of getting organized to deal with powerful market actors. However, this also demonstrates that such new forms of ICT-induced connectivity can also be utilized to push other agendas that were not intended by a communicative intervention.

Although it was not raised by many farmers, the idea that the virtual platform encouraged people to speak their minds which they could hesitate to do in face-to-face communication evoked the notion of "digital dualism." Jurgensen (2011) highlighted that a separate digital and physical sphere affects the way people behave that could potentially create a "second self." We believe that this could pique interest in future research on understanding the diverse implications of ICTenabled communicative interventions in the management of collective action problems.

\subsection{External validity}

Even though the anonymity among farmers ensured internal validity by minimizing a potential bias that could have come from farmers' interaction in the non-communicating groups if they had known each other, the conditions of the experiments do not reflect the real-life of farmers. In reality, it is less likely or not commonly the case that farmers in a community do not know each other. In this regard, our case study was not free from the enduring epistemic dilemma of choosing from or balancing between internal and external validity. In addition, for simplifying the game for farmers and logistical reasons, the design took (not) spraying as the only important factor in late blight occurrence, while in reality, other abiotic factors (e.g., temperature, humidity, rainfall) play role in the likelihood of disease occurrence. Future research can capitalize on this by including, for instance, uncertainty element or multiple scenarios to levels of disease occurrence under different environmental conditions. Finally, in the experiment, the farmers did not have to invest their own money in disease management or group communication. The latter was paid for 
(internet and mobile data) with an average of 25 ETB or 0.85 Euro cents per farmer. As Ostrom (2012) noted, irrespective of the means of communication, it is rare that the opportunity to communicate is costless as someone has to invest money, time, or effort to create and maintain arenas for communication. Likewise, the research project provided the initial spraying investment of 400 ETB (13.60 Euro) per farmer. When designing communicative interventions in collective action problem situations, it is hence important to take into account the sources for the costs of creating a communication space and a common good provision investment.

\section{Conclusion}

Dealing with collective action problems such as the management of late blight requires more than technical information provision or about interdependencies involved in management practices of farmers. In fact, communication practices that are mainly geared towards increasing farmers' awareness of such technical facts could negatively affect collective action. Furthermore, providing social monitoring information about the practices of others when there is already a weak collective action could further promote non-cooperation in the management of the disease. In light of this, expert advisory services and/or provision of relevant technical and social information have to be complemented with interactive communication and deliberation processes that are internally governed or managed by communities. This would help in making the best out of advisory services and monitoring practices that could otherwise have a chance to be counterproductive in managing collective action problems.

From an analytical viewpoint, apart from showing the direction or magnitude of relationships between communicative interventions and collective action performance, employing conceptual perspectives that open the black box and shed light on what really happened during communicative interventions is an important step in understanding how different types of communicative practices facilitate or obstruct collective action in a particular context.

The use of smartphones has demonstrated the potential for such platforms in facilitating networking and connectivity among specially and temporally scattered community members. However, farmers' attempt to use the platform for advancing other agendas would mean that communicative research and/or development interventions need to take into consideration any unintended consequences of using such platforms and how these interplay with the envisioned objective of a communicative intervention in the management of collective action problems.

Supplementary Information The online version contains supplementary material available at https://doi.org/10.1007/s12571-020-01120-0.
Acknowledgments We would like to acknowledge INREF and the International Potato Center (CIP) for co-funding this research and the Ph.D. training of the first author. Additional funding was provided by the CGIAR Research Program on Roots, Tubers and Bananas (RTB) and the US Agency for International Development (USAID) Federal Award no. 663-G-00-09-00420. We thank all farmer participants for their willingness to participate in the experiment and provide valuable information for the research.

Code availability STATA commands and codes used for analysis are available from the corresponding author (E.D) on request.

Funding The research presented here is conducted under a research program called "Responsible life-science innovations for development in the digital age: EVOCA" that is funded by the Wageningen University International Research and Education Fund (INREF).

Data availability All quantitative and qualitative data supporting the findings of this study are available from the corresponding author (E.D) on request.

\section{Compliance with ethical standards}

Conflict of interest The authors declare that they have no conflict of interest.

Ethics approval Obtained from the Wageningen Social Science Ethics Committee

Consent for participation Agreed and signed on a consent form by each participant.

Consent for publication Agreed and signed on a consent form by each participant

Open Access This article is licensed under a Creative Commons Attribution 4.0 International License, which permits use, sharing, adaptation, distribution and reproduction in any medium or format, as long as you give appropriate credit to the original author(s) and the source, provide a link to the Creative Commons licence, and indicate if changes were made. The images or other third party material in this article are included in the article's Creative Commons licence, unless indicated otherwise in a credit line to the material. If material is not included in the article's Creative Commons licence and your intended use is not permitted by statutory regulation or exceeds the permitted use, you will need to obtain permission directly from the copyright holder. To view a copy of this licence, visit http://creativecommons.org/licenses/by/4.0/.

\section{References}

Adam, Lishan. (2012). Understanding what is happening in ICT in Ethiopia: a supply and demand-side analysis of the ICT sector. Evidence for ICT Policy, Action Policy Paper 3. https:// researchictafrica.net/ Accessed 22 Novermber 2019.

Andreoni, J., \& Petrie, R. (2004). Public goods experiments without confidentiality: a glimpse into fund-raising. Journal of Public Economics, 88(7-8), 1605-1623.

Asongu, S., \& Boateng, A. (2018). Introduction to special issue: mobile technologies and inclusive development in Africa. Journal of African Business, 19(3), 297-301. 
Bachi, Benjamin, Sambuddha Ghosh, and Zvika Neeman. (2010). Prisoner's dilemma with talk. http://www.dklevine.com/lectures/ evolution/bachi.pdf Accessed 22 November 2019.

Balliet, D. (2010). Communication and cooperation in social dilemmas: a meta-analytic review. Journal of Conflict Resolution, 54(1), 39-57.

Bekele, B., Abate, E., \& Asefa, A. (2012). Viruses and bacterial wilt disease of potato in western Amhara. In seed potato tuber production and dissemination: experiences, challenges and prospects. In Proceedings of the National Workshop on Seed Potato Tuber Production and Dissemination, BahirDar, Ethiopia, 12-14 March (pp. 241-255).

Bennett, W. L., \& Segerberg, A. (2012). The logic of connective action: digital media and the personalization of contentious politics. Information, Communication \& Society, 15(5), 739-768.

Bochet, O., Page, T., \& Putterman, L. (2006). Communication and punishment in voluntary contribution experiments. Journal of Economic Behavior \& Organization, 60(1), 11-26.

Burke, J. J. (2017). Growing the potato crop. Dublin 7, Ireland: Vita. Equity House: Upper Ormond Quay.

Cabrales, Antonio, Feri, Francesco, Gottardi, Piero and MeléndezJiménez, Miguel. (2016). Can there be a market for cheap-talk information? Some experimental evidence. CEPR Discussion Paper No. DP11206. https://ssrn.com/abstract=2766534. Accessed 25 July 2019.

Campos, H., \& Ortiz, O. (2019). The potato crop: its agricultural, nutritional and social contribution to humankind. Basel: Springer Nature.

Cardenas, J.-C., Ahn, T. K., \& Ostrom, E. (2004). Communication and co-operation in a common-pool resource dilemma: a field experiment. In S. Huck (Ed.), Advances in Understanding Strategic Behaviour (pp. 258-286). London: Palgrave Macmillan.

Cason, T. N., Sheremeta, R. M., \& Zhang, J. (2012). Communication and efficiency in competitive coordination games. Games and Economic Behavior, 76(1), 26-43.

Choi, S., \& Lee, J. (2014). Communication, coordination, and networks. Journal of the European Economic Association, 12(1), 223-247.

Ciancio, A., \& Mukerji K.G. (2008). Integrated management of diseases caused by fungi, phytoplasma and bacteria (Vol. 3). Amsterdam: Springer Science \& Business Media.

Cieslik, K. J., Leeuwis, C., Dewulf, A. R. P. J., Lie, R., Werners, S. E., Van Wessel, M., Feindt, P., \& Struik, P. C. (2018). Addressing socio-ecological development challenges in the digital age: exploring the potential of Environmental Virtual Observatories for Connective Action (EVOCA). NJAS-Wageningen Journal of Life Sciences, 86, 2-11.

Costello, C., Querou, N., \& Tomini, A. (2017). Private eradication of mobile public bads. European Economic Review, 94(2017), 23-44.

Crawford, V. (1998). A survey of experiments on communication via cheap talk. Journal of Economic Theory, 78(2), 286-298.

Croson, R. (2007). Theories of commitment, altruism and reciprocity: evidence from linear public goods games. Economic Inquiry, 45(2), 199-216.

Croson, R., \& Shang, J. (2008). The impact of downward social information on contribution decisions. Experimental Economics, 11(3), 221-233.

Cubitt, R. P., Drouvelis, M., Gächter, S., \& Kabalin, R. (2011). Moral judgments in social dilemmas: how bad is free riding? Journal of Public Economics, 95(3-4), 253-264.

D’Exelle, B., Lecoutere, E., \& Van Campenhout, B. (2012). Equityefficiency trade-offs in irrigation water sharing: evidence from a field lab in rural Tanzania. World Development, 40(12), 2537-2551.

Damtew, E., Tafesse, S., Lie, R., Van Mierlo, B., Lemaga, B., Sharma, K., Struik, P. C., \& Leeuwis, C. (2018). Diagnosis of management of bacterial wilt and late blight in potato in Ethiopia: a systems thinking perspective. NJAS-Wageningen Journal of Life Sciences, $86,12-24$.
Damtew, E., van Mierlo, B., Lie, R., Struik, P., Leeuwis, C., Lemaga, B., \& Smart, C. (2020). Governing a collective bad: social learning in the management of crop diseases. Systemic Practice and Action Research, 33(1), 111-134.

Demissie, Y. T. (2019). Integrated potato (Solanum tuberosum L.) late blight (Phytophthora infestans) disease management in Ethiopia. American Journal of BioScience, 7(6), 123-130.

Dietz, T., Ostrom, E., \& Stern, P. C. (2003). The struggle to govern the commons. Science, 302(5652), 1907-1912.

Fischbacher, U., \& Gachter, S. (2010). Social preferences, beliefs, and the dynamics of free riding in public goods experiments. American Economic Review, 100(1), 541-556.

Franc, G. D. (1998). An introduction to plant pathology and plant disease management. Laramie: University of Wyoming, Cooperative Extension Service.

Garicano, L., \& Wu, Y. (2012). Knowledge, communication, and organizational capabilities. Organization Science, 23(5), 1382-1397.

Graham, S., Metcalf, A. L., Gill, N., Niemiec, R., Moreno, C., Bach, T., Ikutegbe, V., Hallstrom, L., Ma, Z., \& Lubeck, A. (2019). Opportunities for better use of collective action theory in research and governance for invasive species management. Conservation Biology, 33(2), 275-287.

Hashim, M. J., Kannan, K. N., \& Maximiano, S. (2017). Information feedback, targeting, and coordination: an experimental study. Information Systems Research, 28(2), 289-308.

Janssen, M. A., Holahan, R., Lee, A., \& Ostrom, E. (2010). Lab experiments for the study of social-ecological systems. Science, 328(5978), 613-617.

Jurgensen, N. (2011). Digital dualism and the fallacy of web objectivity. Cyborgology. http://thesocietypages.org/cyborgology/2011/09/13/ digital-dualism-and-the-fallacy-of-web-objectivity/. Accessed November 2019.

Khadjavi, M., Lange, A., \& Nicklisch, A. (2017). How transparency may corrupt-experimental evidence from asymmetric public goods games. Journal of Economic Behavior \& Organization, 142, 468481.

Kirk, W. W., \& Wharton, P. S. (2014). Fungal and bacterial disease aspects of potato production. In R. Navarre \& M. Pavek (Eds.), The Potato, Botany, Production and Uses. Chapter 11 (pp. $167-$ 201). Boston: CABI.

Klerkx, L., \& Leeuwis, C. (2008). Matching demand and supply in the agricultural knowledge infrastructure: experiences with innovation intermediaries. Food Policy, 33(3), 260-276.

Klerkx, L., Hall, A., \& Leeuwis, C. (2009). Strengthening agricultural innovation capacity: are innovation brokers the answer? International Journal of Agricultural Resources, Governance and Ecology, 8(5-6), 409-438.

Leeuwis, C. (2004). Communication for rural innovation. Rethinking agricultural extension (3rd ed.). Oxford: Blackwell Science.

Leeuwis, C. (2010). Changing views of agricultural innovation: implications for communicative intervention and science. In F. G. Palis (Ed.), Research to Impact: Case Studies for Natural Resource Management for Irrigated Rice in Asia (pp. 15-32). Manila: International Rice Research Institute.

Leeuwis, C., \& Aarts, M. N. C. (2011). Rethinking communication in innovation processes: creating space for change in complex systems. The Journal of Agricultural Education and Extension, 17(1), 21-36.

Leeuwis, C., \& Aarts, M. N. C. (2020). Rethinking adoption and diffusion as a collective social process: towards an interactional perspective. In The innovation revolution in agriculture (pp. 95-116). Cham: Springer.

Marks, M. B., \& Croson, R. T. A. (1999). The effect of incomplete information in a threshold public goods experiment. Public Choice, 99(1-2), 103-118.

Martin, J. M., Gonzalez, C., Juvina, I., \& Lebiere, C. (2014). A description-experience gap in social interactions: information about 
interdependence and its effects on cooperation. Journal of Behavioral Decision Making, 27(4), 349-362.

Maumbe, B. M., \& Okello, J. J. (2013). Uses of information and communication technology (ICT) in agriculture and rural development in sub-Saharan Africa: experiences from South Africa and Kenya. In B. M. Maumbe \& J. Okello (Eds.), Technology, Sustainability, and Rural Development in Africa (pp. 113-134). Hershey: IGI Global.

Mekonen, S., Alemu, T., Kassa, B., \& Forbes, G. (2011). Evaluation of contact fungicide spray regimes for control of late blight (Phytophthora infestans) in southern Ethiopia using potato cultivars with different levels of host resistance. Tropical Plant Pathology, $36,21-27$.

Milinski, M., Sommerfeld, R. D., Krambeck, H. J., Reed, F. A., \& Marotzke, J. (2008). The collective-risk social dilemma and the prevention of simulated dangerous climate change. Proceedings of the National Academy of Sciences, 105(7), 2291-2294.

Miller, J. S., Nolte, P., Olsen, N., Miller, T., Bohl, B., \& Thornton, M. (2006). Late blight management action plan for potatoes. Moscow: University of Idaho Extension.

Olson, M. (2009). The logic of collective action (Vol. 124). Cambridge: Harvard University Press.

Opdam, P., Coninx, I., Dewulf, A., Steingröver, E., Vos, C., \& van der Wal, M. (2016). Does information on landscape benefits influence collective action in landscape governance? Current Opinion in Environmental Sustainability, 18, 107-114.

Ostrom, E. (1990). Governing the commons - the evolution of institutions for collective action. New York: Cambridge University Press.

Ostrom, E. (1992). Crafting institutions for self-governing irrigation systems. San Francisco: Institute for Contemporary Studies.

Ostrom, Elinor. (1999). Design principles and threats to sustainable organizations that manage commons. In paper for electronic conference on small Farmer's economic organizations, organized by Julio a. Berdegue. Santiago, Chile.

Ostrom, E. (2009). Beyond markets and states: polycentric governance of complex economic systems. Prize Lecture, December 8, 2009. Workshop in Political Theory and Policy Analysis, Indiana University, Bloomington, IN 47408, and Center for the Study of Institutional Diversity. Tempe: Arizona State University.

Ostrom, E. (2012). Experiments combining communication with punishment options demonstrate how individuals can overcome social dilemmas. Behavioral and Brain Sciences, 35(1), 33-34.

Ostrom, E., \& Walker, J. (1991). Communication in a commons: cooperation without external enforcement. Laboratory Research in Political Economy, 287-322.

Pande, Arun, Bhushan G. Jagyasi, and Ravidutta Choudhuri. (2009). Late blight forecast using mobile phone-based agro advisory system. In International Conference on Pattern Recognition and Machine Intelligence (pp. 609-614). Springer, Berlin, Heidelberg.

Peng, X., Hendrikse, G., \& Deng, W. (2018). Communication and innovation in cooperatives. Journal of the Knowledge Economy, 9(4), 1184-1209.

Pernezny, Ken, Monica Elliott, Aaron Palmateer, and Nikol Havranek. (2016). Guidelines for identification and management of plant disease problems: part II. Diagnosing plant diseases caused by fungi, bacteria and viruses. Plant Pathology Department, UF/IFAS Extension publication.
Petty, R. E., \& Cacioppo, J. T. (1986). Communication and persuasion: the elaboration likelihood model of persuasion (pp. 1-24). New York: Springer.

Reuben, E., \& Riedl, A. (2013). Enforcement of contribution norms in public good games with heterogeneous populations. Games and Economic Behavior, 77(1), 122-137.

Rogers, E. M. (1995). Diffusion of innovations. New York: Free Press.

Sell, J., \& Wilson, R. K. (1991). Levels of information and contributions to public goods. Social Forces, 70(1), 107-124.

Smith, E. A. (2010). Communication and collective action: language and the evolution of human cooperation. Evolution and Human Behavior, 31(4), 231-245.

Steingröver, E. G., Geertsema, W., \& van Wingerden, W. K. R. E. (2010). Designing agricultural landscapes for natural pest control: a transdisciplinary approach in the Hoeksche Waard (The Netherlands). Landscape Ecology, 25(6), 825-838.

Tafesse, S., Damtew, E., van Mierlo, B., Lie, R., Lemaga, B., Sharma, K., Leeuwis, C., \& Struik, P. C. (2018). Farmers' knowledge and practices of potato disease management in Ethiopia. NJAS-Wageningen Journal of Life Sciences, 86, 25-38.

Tsedaley, B. (2014). Late blight of potato (Phytophthora infestans) biology, economic importance and its management approaches. Journal of Biology, Agriculture and Healthcare, 4(25), 215-225.

Weimann, J. (1994). Individual behavior in a free-riding experiment. Journal of Public Economics, 54(2), 185-200.

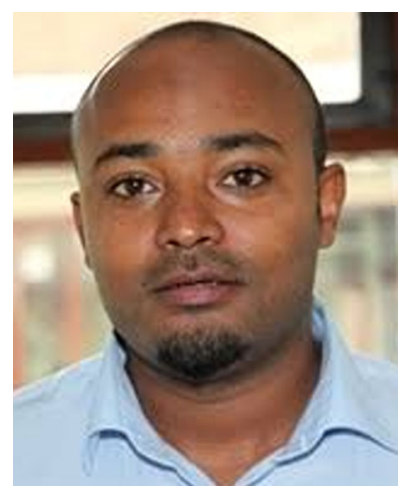

Elias Damtew has a $\mathrm{PhD}$ from the School of Social Science at Wageningen University \& Research. His research interest lies in understanding socialtechnical change processes in agri-food and socio-ecological systems. He is now working as a researcher at Wageningen University and CGIAR Research Program on Roots, Tubers and Banana, and studies scaling science and practice in different research-for-development projects.

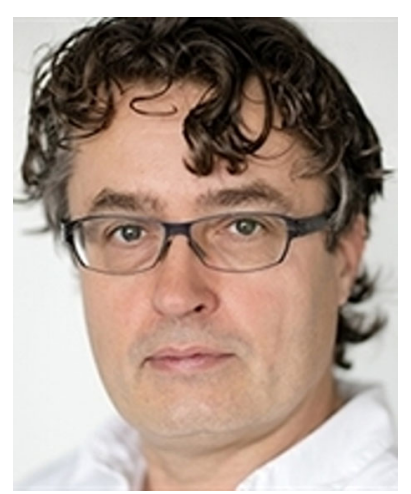

Cees Leeuwis is a professor of Knowledge, Technology and Innovation at the Social Science School of Wageningen University and Research. He studies processes of socio-technical innovation and transformation in networks; collaboration between different disciplines; research for development policy; the functioning of innovation support systems; and the role of innovation platforms, communication, extension, and brokers therein. 


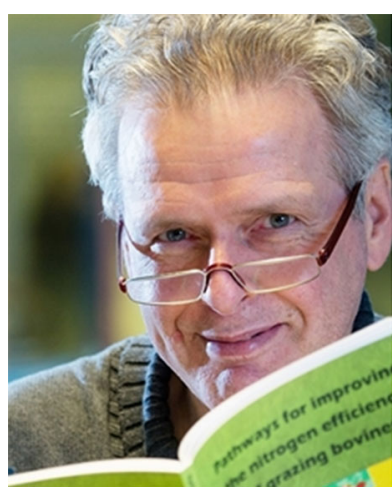

Paul C Struik is a professor at the Centre for Crop Systems Analysis, Wageningen University and Research. He has a track record in grassland science, agronomy, and crop physiology. Over the last decade, the main focuses of his research activities were on seed systems, Agrobiodiversity, linking ecophysiology, and genetics of complex traits through modeling and modeling of $\mathrm{C} 3$ and $\mathrm{C} 4$ photosynthesis at different scales and in different dimensions

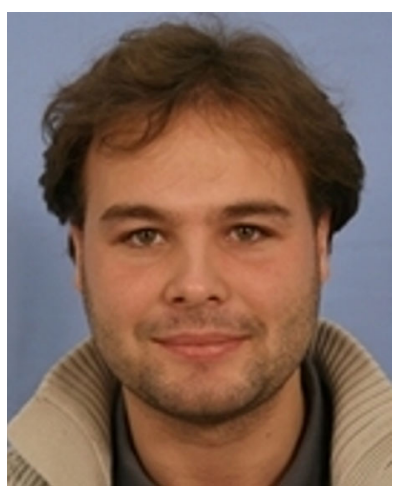

Francesco Cecchi is a postdoctoral researcher at the Development Economics Group of Wageningen University. His main field of research is development economics, and he is particularly interested in behavioral and experimental economics. In his current research, he focuses on microfinance, insurance, and risk.

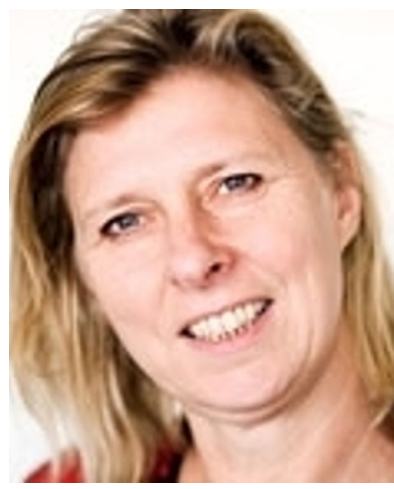

Barbara van Mierlo is an associate professor, working as a sociologist at the Knowledge, Technology and Innovation Group at Wageningen University. She studies processes of transformative, systemic change towards sustainability and their intersection with everyday social practices. Being actively engaged in these processes, special interests include the significance and features of interactive learning and discursive strategies, the value of changeoriented evaluation, emergence of reflexivity, responsible innovation, and transdisciplinary collaboration.

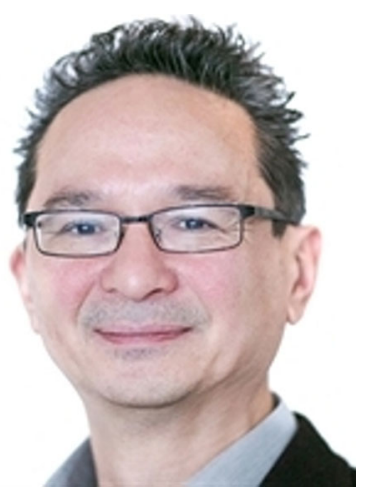

and intercultural communication.
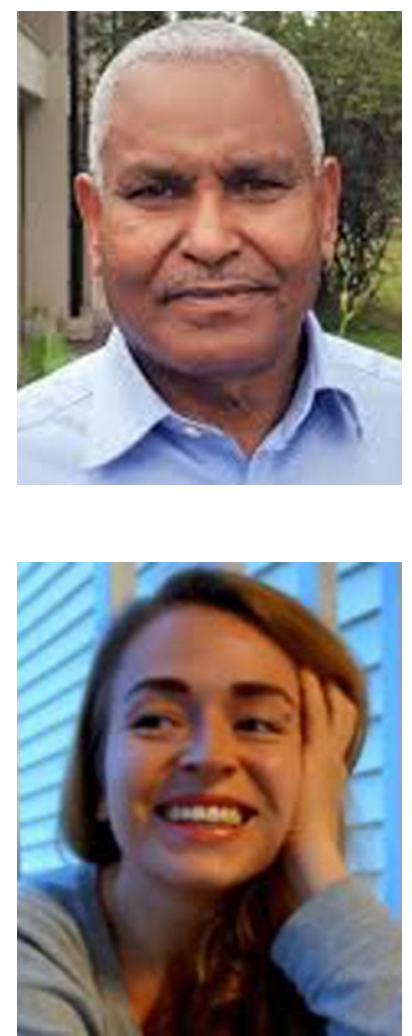

ment challenges related to sustainable livelihoods.
Rico Lie is an assistant professor, working as social anthropologist at the research group Knowledge, Technology and Innovation, Wageningen University, The Netherlands. He previously worked at the University of Brussels in Belgium and the universities of Nijmegen and Leiden in The Netherlands. At Wageningen University, he is an assistant professor in international communication with an interest in the areas of development communication

Berga Lemaga is a senior agronomist and a CIP-Ethiopia country manager. He also served as a research and extension director at the Ethiopian Agricultural Transformation Agency, led a regional potato and sweet potato improvement network of ten countries in Sub-Saharan Africa, and managed regional potato projects. His research and development work focuses on the seed system, breeding, and agronomy of roots and tuber crops

Katarzyna Cieslik has a $\mathrm{PhD}$ in Economics and Management from the Université Libre de Bruxelles in Belgium. She is a research scholar at the Department of Geography, University of Cambridge. Her research focuses on the interactions among society, policy, and environment, and their implications for sustainable development in the Global South. She is particularly interested in the agency, entrepreneurship, and civic potency of individuals in addressing the pressing develop- 